DOI: $10.25100 /$ pfilosofica.v0i53.11187

\title{
EXPERIENCIAS INAUDIBLES DEL HORROR. ENTRE LA ANTICIPACIÓN EN LEVINAS Y LA REMEMORACIÓN EN LEVI
}

Federica Scherbosky

Instituto de Ciencias Humanas, Sociales y Ambientales. Consejo Nacional de Investigaciones Científicas y Técnicas. Universidad Nacional de Cuyo

\begin{abstract}
Resumen
¿Por qué volver a pensar Auschwitz? ¿Qué sentido tendría si ya se ha abordado innumerables veces? Por un intento de comprensión del horror que no descansa y en ese marco destacamos los aportes de Emmanuel Levinas $y$ de Primo Levi. El primero en Algunas reflexiones sobre la filosofía del hitlerismo (1934) anuncia y denuncia la estructura de exterminio que esta implicaba. El segundo en Si esto es un hombre escrito en 1946 y publicado en 1947, bajo el imperativo del testimonio, sostiene que sobrevivir tuvo sentido para poder contar lo sucedido. Ambos textos tuvieron dificultades para ser oídos y consideramos que esto se debe a la premura de sus denuncias. Esas experiencias inaudibles lo fueron tanto por el objeto del relato-un horror desconocido hasta entonces- como por un régimen de sensibilidad que aún no podía abrirse a semejante escucha.
\end{abstract}

Palabras clave: nazismo; horror; denuncia; testimonio; humanismo.

Cómo citar este artículo: Scherbosky, F. (2021). Experiencias inaudibles del horror. Entre la anticipación en Levinas y la rememoración en Levi. Praxis Filosófica, (53), 157-182. https://doi.org/10.25100/ pfilosofica.v0i53.11187

Recibido: 27 de julio de 2020. Aprobado: 28 de septiembre de 2020 . 


\title{
Inaudible experiences of horror. Between anticipation in Levinas and remembrance in Levi
}

\author{
Federica Scherbosky ${ }^{1}$
}

\begin{abstract}
Why think Auschwitz again? What's the point if it's already been addressed countless times? For an attempt to understand the horror that does not rest, and in that context we highlight the contributions of Emmanuel Levinas and Primo Levi. The first in Some Reflections on the Philosophy of Hitlerism (1934) announces and denounces the extermination structure involved. The second in If this is a man written in 1946 and published in 1947, under the imperative of testimony, maintains that surviving made sense in order to be able to tell what happened. Both texts had difficulty being heard and we consider this is due to the haste of their denunciations. These inaudible experiences were so both because of the object of the story - a horror unknown until then - and because of a regime of sensibility that could not yet open up to such listening.
\end{abstract}

Keywords: Nazism; Horror; Denunciation; Testimony; Humanism.

${ }^{1}$ Investigadora del Consejo Nacional de Investigaciones Científicas y Técnicas (CONICET) en el Instituto de Ciencias Humanas, Sociales y Ambientales, (INCIHUSA), Mendoza, Argentina. Docente efectiva en la Facultad de Educación de la Universidad Nacional de Cuyo, cátedra de Antropología Filosófica. Actualmente se desempeña también como Directora de Posgrado en la Facultad de Educación. Profesora de Filosofía egresada de la Universidad Nacional de Cuyo (2008). Doctora en Filosofía en la Universidad de Buenos Aires (2014). Participa en Proyectos de Investigación en Filosofía Práctica e Historia de las Ideas. Ha publicado artículos en revistas especializadas y capítulos de libro, acerca de filosofía intercultural, teorías del reconocimiento, problemática de la cultura y la alteridad. Su tema de trabajo actual es el Movimiento Antropofágico Brasilero, específicamente las categorías de subjetividad, racionalidad y conflicto, en relación con las teorías del reconocimiento y los planteos de la diversidad.

E-mail: fedescherbo@gmail.com ORCID: 0000-0002-0601-8979 


\title{
EXPERIENCIAS INAUDIBLES DEL HORROR. ENTRE LA ANTICIPACIÓN EN LEVINAS Y LA REMEMORACIÓN EN LEVI
}

\author{
Federica Scherbosky \\ Instituto de Ciencias Humanas, Sociales y Ambientales. \\ Consejo Nacional de Investigaciones Científicas y Técnicas. \\ Universidad Nacional de Cuyo
}

\section{Introducción: acerca de la imposibilidad de escuchar el horror}

Mucho se ha dicho ya sobre el horror de los campos de concentración y extermino bajo el régimen nazi. Sabemos de sus tramas históricas, políticas, económicas e incluso de sus devenires jurídicos. No obstante, volvemos una y otra vez a esos sitios de la historia, de la memoria, de los relatos, con múltiples propósitos, entre los cuales nos interesa especialmente el intento de comprensión de algo que siempre se nos escapa y en el mismo sentido de aquello que no podemos terminar de escuchar. Eso que pensamos como experiencias inaudibles en función, por un lado, del objeto de la escucha -el horror- y por otro, de un régimen de sensibilidad que presenta obturada su capacidad de escucha de aquello que escapa el parámetro de sus posibilidades. No hay forma de escuchar, de ver, de percibir, de captar aquello que está por fuera de nuestras posibilidades de registro, en términos sensibles, y más aún en términos de comprensión de aquello que ni siquiera podemos terminar de captar.

Estas instancias sobrevuelan la idea de la necesidad de volver a pensar Auschwitz, de reincidir en un intento de comprensión, aunque este sea desde un primer momento, algo vano. Reincidencia incansable que nos empuja desde la filosofía a intentar comprender aquello que humanamente 
se sigue tornando incomprensible; $y$, justamente por ello, azuzamos una vez más las preguntas: ¿Qué es lo que vuelve al nazismo incomprensible? ¿Es efectivamente incomprensible o es, en realidad, humanamente intolerable? E incluso, ¿desde qué perspectiva de lo humano se vuelve intolerable?

Nos centraremos aquí en dos autores y casi particularmente en dos textos, que aun con pretensiones y recorridos muy diferentes, tienen algunos puntos de contacto que pretendemos poner en diálogo. Se trata de Emmanuel Levinas y Primo Levi.

¿Por qué estos dos autores? ¿Qué es lo que podría vincularlos, más allá de haber vivenciado en carne propia el horror del nazismo, como tantos otros pensadores? El punto de unión de ambos es la denuncia y la responsabilidad para con el otro. Tanto Levinas como Levi generan instancias de denuncia del horror muy prontamente, instancias que consideramos de no menor importancia y que, de hecho, podemos arriesgar, es causa de la dificultad que tienen de ser oídos. Esta es nuestra hipótesis central. En la denuncia inmediata de ambos -tanto en la anticipación, como en la rememoración- se pone en evidencia una relación con el otro en términos de responsabilidad, como capacidad de responder. En el caso de Levinas este texto será un quiebre en su relación con Heidegger y marcará el paso de la existencia (fundante en la filosofía de su maestro) al existente, en tanto relación con el otro concreto. Se trata del "cara a cara" que nos constituye, a priori, como humanos. Y en el caso de Levi, a pesar del miedo a no ser escuchado y comprendido, avanza en su escritura testimonial como necesidad ética y política; porque hay quienes ya no están para contar lo sucedido y para que además esto no vuelva a suceder.

Nos interesa resaltar también que la prontitud en la denuncia pone en jaque la pretensión de objetividad moderna, como aquella distancia necesaria en la construcción de la historia, ya que cada uno, desde su lugar, articula un relato fundamental para el análisis de Auschwitz, de manera casi inmediata a los hechos.

Cabe destacar, y quizás sea parte de las conclusiones a las que arribemos, que no necesariamente las denuncias realizadas con posterioridad fueron más escuchadas, solo que consideramos que con el tiempo fue mutando, en algún sentido al menos, la capacidad de escuchar el horror. Un cierto registro del horror fue horadando poco a poco el régimen de lo sensible para que al menos las denuncias posteriores no fueran negadas. Dudamos de que fueran efectivamente escuchadas, pero al menos no fueron negadas en su totalidad. De hecho, buena parte de las instancias que torturaban a Levi mientras se pensaba en su rol de testigo era que nadie le creería, que la gente no podría comprender semejante horror y que en función de ello lo negaría. 
Decidimos, en primer lugar, por una cuestión meramente cronológica, retomar un texto que Emmanuel Levinas, en su condición de filósofo y judío lituano, publicó en 1934 con el inquietante título de Algunas reflexiones sobre la filosofía del hitlerismo. A partir de éste pretendemos reflexionar acerca de algunas cuestiones fundamentales, aunque el texto en sí abra innumerables perspectivas de análisis. Nos interrogamos por la figura del autor y cuál es la importancia de este texto en su obra. Luego abordaremos la tesis fundamental de su escrito y qué implicancias se abren a partir de allí.

En segundo lugar, nos centramos en el clásico texto de Primo Levi titulado Si esto es un hombre que fue escrito en 1947. Libro fundamental de la literatura concentracionaria, es el primer escrito de lo que se publica actualmente como Trilogía de Auschwitz, compuesto en segundo lugar por La Tregua (1963) y seguido por Los hundidos y los salvados (1986). Analizamos su denuncia, su necesidad de contar lo sucedido y la complejidad del lugar del testigo.

Por último, habilitamos un espacio de cruce entre ambos autores a fin de reflexionar sobre las posibilidades de trascender -aun en la inmanenciaa pesar del horror.

\section{La anticipación del horror en un escrito temprano de Emmanuel Levinas}

El 12 de enero de 1906 nació Levinas en la ciudad de Kovno en Lituania. Su familia formaba parte de la pequeña burguesía judía, lo que le permitió crecer en un ambiente de comunidades judías intelectuales. Fue hijo de Jehiel Levinas y de Débora Gurvic, y el mayor de tres hermanos. En su casa se hablaba ídisch y ruso, lo que le posibilitó acceder a obras de autores rusos como Gogol, Lermontov, Tolstoy y sobre todo Fiódor Dostoievski. Todas las temáticas éticas y metafísicas que planteaban estos autores despertaron un gran interés en él. De hecho, afirma que sus personajes lo introdujeron "al problema filosófico entendido como el del sentido de lo humano, como búsqueda del famoso sentido de la vida" (Levinas, 2008, p. 24). También desde pequeño aprendió hebreo y estudió el talmud.

En 1914 emigran a causa de la primera guerra mundial, instalándose en Ucrania donde vive la revolución bolchevique que avanza por toda esa región. Al tiempo regresa a Lituania, donde recibe la enseñanza media. En 1923 se traslada a Estrasburgo (Francia), donde estudia filosofía con Maurice Blondel hasta 1927.

Decide pasar su último año como universitario en Friburgo, para asistir a los últimos cursos de Husserl y los primeros de Heidegger. Este contacto con los fundadores de la fenomenología será determinante para 
su vida intelectual. Se dedica, de hecho, a introducir la fenomenología en Francia, donde publica su tesis de doctorado titulada Teoría de la intuición en la Fenomenología de Husserl en 1930, por el cual recibe un premio del Instituto de Francia. En el mismo año se casa con Margarita Levi y un año después se nacionaliza francés. Entre 1931 y 1932 asiste a los encuentros filosóficos en casa de Gabriel Marcel, y se convierte en uno de los primeros colaboradores de la revista Esprit, fundada por Emmanuel Mounier.

1933 marca un quiebre en su vida, ya que el idilio de Friburgo se ve cortado por el ascenso del nazismo y la adhesión de Heidegger al mismo, a quien no le perdonará nunca su afiliación al Partido Nazi. A partir de este quiebre se vuelca nuevamente a las fuentes judías, tanto en la participación activa en la comunidad, como en la publicación de sus primeros textos judios. Participa de la administración de la Alianza Israelita Universal y trabaja como docente en sus escuelas donde se brindaba educación a los judíos establecidos en la cuenca mediterránea que no contaban con una formación occidental.

El quiebre de 1933 lo lleva a adoptar una postura crítica con respecto al pensamiento filosófico heideggeriano. Y si bien nunca deja de admitir su admiración por Ser y Tiempo (1927), advierte una profunda complicidad entre la ontología heideggeriana y el nazismo. Cuestión que trata en el texto que nos ocupa, publicado en 1934 y en De la evasión, que sale a la luz en 1935.

A partir de esta ruptura y sus consecuentes búsquedas, encuentra como guía La estrella de la redención de Franz Rosenzweig, que influirá decisivamente en su pensamiento como filósofo judío.

En el año de 1939, ya iniciada la Segunda Guerra Mundial, sirve a los aliados como intérprete de ruso y alemán en las Fuerzas Armadas aliadas. $\mathrm{Al}$ año siguiente cae prisionero y permanece durante toda la guerra en un campo de concentración en Hannover, Alemania, pero su condición de militar francés lo salva del trato que recibieron otros judíos. Incluso puede seguir con su labor intelectual, de lo que da prueba la obra De la existencia al Existente que comienza a escribir durante el cautiverio y que publica en 1947. En este libro vuelve a poner en cuestión la fenomenología de Heidegger y si bien empieza a hacerlo en el texto que trabajamos aquí, como así también en De la evasión, en 1947 lo realiza de manera más acabada. $\mathrm{Su}$ giro hacia la alteridad en términos del cara a cara lo aleja de la noción de existencia para pensar en el existente. Alteridad constitutiva de la propia subjetividad de manera apriorística (Levinas, 2006b). Hasta su muerte sigue dictando conferencias, seminarios y publicando artículos y recopilaciones, que retoman sus dos vertientes: la filosófica, donde vuelve a sus grandes 
obras como Totalidad e Infinito (1961) y De otro modo que ser o más allá de la esencia (1974). En cuanto a sus escritos judíos, publica en 1963 Dificil libertad y luego varios escritos con sus reflexiones talmúdicas, entre los que se encuentran Cuatro lecturas talmúdicas, De lo sagrado a lo santo, Cinco nuevas lecturas talmúdicas, entre otros ${ }^{2}$.

Hasta aquí esta breve reseña de su vida y obra, con la finalidad de saber con quién dialogamos, qué cosas lo marcaron y las diferentes vicisitudes que tuvo que sortear.

Ahora nos interesa destacar la importancia del escrito que referenciamos. Primeramente, nos sorprende el título, ya que conviven en él tanto la filosofía como el hitlerismo, conceptos que podríamos pensar como contradictorios, ya que uno indicaría la voluntad de comprender lo humano, de guiarlo, de buscar sus acciones y características más nobles, mientras que el otro -más a esta altura de la historia- implica el genocidio, la discriminación, la humillación, la deshumanización sistemática, entre otras.

Cabe aclarar que Levinas hace referencia al hitlerismo no como la doctrina propagada por Hitler, ni la filosofía de los hitlerianos, ya que sostiene que la filosofía del hitlerismo rebasa estas instancias particulares. Así afirma al hitlerismo en su dimensión colectiva, como un estado de ánimo, de modo impersonal. Postula a su vez que este movimiento encarna una filosofía primaria, en tanto empuje de fuerzas elementales. Estas fuerzas elementales implican en sí sentimientos elementales, y allí es donde radica la dimensión filosófica para el autor, puesto que sostiene que estos sentimientos expresan la actitud primera de un hombre frente a lo real y a su destino.

Miguel Abensour a propósito de la obra del filósofo lituano sostiene la incomodidad de postular estos conceptos conjuntamente. No obstante, acordamos con Levinas, en que, si bien da un cierto resquemor, al saber cómo concluyó la historia, es la misma filosofía la que habilita esta posibilidad. Quizás ya comenzamos a adentrarnos en uno de los temas centrales de la obra, pero seguimos al autor en el Post- Scriptum que realiza en 1990 para una nueva edición del artículo en la revista norteamericana Critical Inquiry, donde afirma que es la misma filosofía la que entraña la posibilidad de este "Mal Elemental". En palabras del mismo Levinas:

El artículo nace de una convicción: que la fuente de la sangrienta barbarie del nacionalsocialismo no está en ninguna anomalía contingente de la

${ }^{2}$ En su mayor parte la presente reseña bibliográfica ha sido extraída del estudio introductorio que realiza Manuel Mauer a la obra de Levinas titulada Dificil Libertad. De igual modo fue cotejada y ampliada con otros documentos y fuentes, entre las que nos interesa destacar el trabajo de García González y Gallardo Cervantes (2001). 
razón humana, ni en ningún malentendido ideológico accidental. Hay en este artículo la convicción de que esta fuente se vincula a una posibilidad esencial del "Mal elemental" al que la buena lógica podía conducir y del cual la filosofía occidental no estaba suficientemente a resguardo (Levinas, 2006a, p. 23).

Es la misma razón la que entraña esta posibilidad, seguramente no como necesidad sine qua non, pero sí al menos como riesgo, como aquello que quizás se presenta de modo contradictorio y casi impensable, pero que es viable que suceda.

Muchos aportes encontramos hoy al respecto, pero lo retomamos como la principal contribución de la Escuela de Frankfurt. Es la misma razón occidental, el mismo progreso y la misma filosofía occidental iluminista la que albergaba el peligro que conduciría a Auschwitz. Era una de sus posibilidades, frente a las cuales no se estuvo preparado. No obstante, no creemos que haya una teleología que conduzca directamente allí, como así tampoco una dualidad entre la civilización y el progreso moderno, por un lado, y la barbarie a la que condujo, por el otro. Asumimos más bien las luces y las sombras de una modernidad absolutamente compleja, por lo que no podemos afirmar sueltamente que la modernidad fue una sola, que implicó sólo una racionalidad vacía que devino en Auschwitz, pero sí que ha sido una parte fundamental de este proceso.

El otro gran señalamiento de Levinas es que, si bien explicita este peligro acerca del Mal Elemental en el Post scriptum en 1990, ya se encuentra el señalamiento en el texto que nos ocupa, de 1934; mientras que se hace explícito en los frankfurtianos pos Segunda Guerra, si pensamos por ejemplo en La dialéctica de la Ilustración, escrita en EEUU en 1944.

Levinas anticipa el terror de la guerra, es capaz de dimensionar el horror que se avecinaba y lo hace saber. No permanece como una intuición posible, o a modo de comentario dentro de algún círculo íntimo. Escribe el artículo meses después de la ascensión de Hitler en 1933, y ya en 1934 el texto sale a la luz. Incluso sostiene el autor -con una claridad espasmódicaque "este artículo apareció en Esprit, revista del catolicismo progresista de vanguardia, en 1934, casi al día siguiente de la llegada de Hitler al poder" (Levinas, 2006a, p. 23).

Esto nos permite pensar en las alternativas existentes, en la anticipación fáctica que un sujeto como Levinas no sólo logra articular, sino que además pretende hacer público. Cabe destacar que no se trata, según él, exclusivamente de la persecución a los judíos, por sentirse parte activa de esa comunidad, o de la exclusión de otras minorías. El intento de comprensión 
que ensaya Levinas implica a la humanidad en su conjunto, pues es ésta la que para el autor está en juego en la articulación de una filosofía de hitlerismo. De hecho, concluye el escrito afirmando:

Tal vez hayamos conseguido mostrar que el racismo no se opone sólo a tal o cual punto particular de la cultura cristiana y liberal. No es tal o cual dogma de democracia, de parlamentarismo, de régimen dictatorial o de política religiosa lo que está en juego. Es la humanidad misma del hombre (Levinas, 2006a, p. 23).

Esta es la tesis que demuestra en este escrito, con una lucidez y una claridad extrañas a su época. Su comprometida vida judía, pero sobre todo su compromiso con la humanidad en su conjunto no le permite quedarse al margen, y más aún en lo que respecta a su relación con Heidegger. Luego de una gran admiración y respeto, de verse influenciado con su pensamiento, e incluso darse a la tarea de introducirlo en el pensamiento francés no logra comprender cómo es que éste adhiere a semejante proyecto de deshumanización y muerte. No sólo le cuestiona su afiliación al partido nazi y su estadía como Rector de la Universidad de Friburgo ${ }^{3}$, sino que cree que en su mismo proyecto filosófico hay una profunda complicidad con las cuestiones que entraña el nazismo.

Curiosamente Heidegger no es nombrado ni una sola vez en el texto, aunque las referencias teóricas y vivenciales son más que claras, su nombre permanece ausente. Como si ni siquiera pudiera expresar el dolor, la desilusión y la angustia que solo su mención evoca.

¿Pero qué es lo que aporta Levinas con este texto? ¿Cuál es su búsqueda?

Pretende, por un lado, comprender y explicitar la relación de Heidegger con el nazismo, y situarse en una postura teórica crítica al respecto. Esta crítica lo hace emprender otras vías, y serán estas búsquedas las que lo reconectarán con ideas centrales del judaísmo.

Por otro lado, lleva a cabo un riguroso análisis fenomenológico del hitlerismo, y desde este particular modo de comprenderlo realiza aportes fundamentales. No está interesado en hacer análisis de las coyunturas causantes del hitlerismo, sino que busca, como sostiene Miguel Abensour

${ }^{3}$ Heidegger asume el 27 de mayo de 1933, pronunciando un discurso titulado La autoafirmación de la Universidad Alemana más conocido como "El discurso del Rectorado", del cual se le piden explicaciones tiempo después de finalizada la guerra. Varios años más tarde, en la década del sesenta, concede una entrevista al semanario alemán Der Spiegel, donde hizo algunas aclaraciones al respecto, pero no se retracta de sus acciones y considera que ha sido mal interpretado. La entrevista se realiza el 23 de septiembre de 1966 y se publica, a pedido de Heidegger, luego de su muerte en 1976, con el título "Solo un dios podrá salvarnos". 
"aprehender el hitlerismo con una profundidad sin par, descubrir el estrato en el que se desarrollan y elaboran las ideologías y los discursos más estrictamente políticos" (Levinas, 2006a, p. 38). O como afirma en otro momento de su análisis que "el hitlerismo se aborda indirectamente, a través del prisma de su filosofía, pues se considera que esta filosofía nos permitirá llegar al centro del fenómeno, al punto nodal a partir del cual podremos deducir sus características esenciales y hacerlas evidentes" (Levinas, 2006a, p. 34).

Y en el análisis de la filosofía del hitlerismo lo que Levinas postula como esencial es la relación con el cuerpo y con el tiempo que éste genera. Tras años de intentos de la humanidad por liberarse de la tiranía del tiempo, de un pasado determinante y de un futuro repetitivo, el hitlerismo retoma la temática, pero busca generar una atadura, una ligazón indestructible a ese tiempo que oprime. Del mismo modo sucede con el cuerpo, ya que fomenta -como conceptualiza Levinas- un ser engarzado al cuerpo, pero que ni siquiera se piensa en tanto unidad del ser humano. No hay unidad en el hombre, sino sólo primacía del cuerpo, de lo biológico, de aquello que marca y de lo cual no se puede escapar. Se destaca y promueve el valor de la sangre, donde puede conjugar la atadura al tiempo y al cuerpo simultáneamente. La marca de la sangre, en tanto determina el pasado, los genes, la raza, propicia un profundo engarce al cuerpo, cuerpo a su vez arraigado en una historia, también determinante y de la que no se puede salir. Es la imposibilidad de futuro como proyección de la diferencia.

La problemática del cuerpo se encuentra completamente atravesada por la relación de Levinas con Heidegger, ya que -como nos dice AbensourLevinas pretende ir más allá de la cuestión del cuerpo, para desentrañar cuál es la posición del ser que se esconde bajo el encadenamiento biológico. Y aquí polemiza con su maestro alemán, puesto que asevera que es la estructura heideggeriana de comprensión del ser como preocupación la que posibilita el ser como encierro. El ser como finitud, en tanto ser para la muerte, constituye un horizonte insuperable para el Dasein.

Levinas afirma entonces que, en esta preocupación por comprender el ser, por comprenderse, por ser uno, el ser se queda encerrado en sí mismo y posibilita el encadenamiento que vendrá a arraigarse con el hitlerismo. Frente a esto él propone ver más allá del ser, buscar una relación anterior a la comprensión que permita reemplazar la preocupación -hermenéutica- del ser, por la responsabilidad -ética- por el otro hombre (Levinas, 2006b) ${ }^{4}$.

${ }^{4}$ Destacamos entonces este escrito de Levinas como fundante de sus planteos filosóficos posteriores, ya que a partir de su crítica al pensamiento de Heidegger habilita una impronta ética que será basal en toda su obra. Se trata, como ya mencionamos en el texto, del paso 
El autor analiza cómo el judaísmo, el cristianismo y el liberalismo encuentran modos de burlar esta atadura al tiempo, modos de sortear el peso de un pasado que oprime y condena a la repetición. Puesto que es el pasado en tanto repetición de lo ya sido, en tanto determinante absoluto lo que pesa sobre la pretensión de libertad del presente.

En el judaísmo Levinas postula el perdón como la posibilidad de crear algo nuevo, como un juego temporal en el que consigue liberarse el presente de la carga del pasado y recomenzar. Solo así puede situarse de modo libre en el presente, modificando la irreversibilidad misma del tiempo.

En el cristianismo, además de la herencia judía con respecto a la modificación temporal del perdón, encontramos la Cruz que libera, $y$ esta "liberación es de cada día por la Eucaristía que triunfa sobre el tiempo. La salvación que el cristianismo quiere aportar vale por la promesa de recomenzar lo definitivo" (Levinas, 2006a, p. 9). Hay una diacronicidad temporal aquí también, ya que en cada eucaristía hay una nueva entrega, una nueva muerte, una nueva redención, un nuevo pacto. Es un pasado siempre en juego, siempre vuelto a poner en cuestión. Podemos incluir al bautismo dentro de los núcleos que generan una modificación temporal aunque el autor no lo menciona-. Este también produce desde el presente un borramiento del pasado, de aquella mancha, de aquel pecado original con el que se nace indefectiblemente. Es, una vez más, la posibilidad de recomenzar de otro modo desligándose así de los determinismos temporales.

El liberalismo en cambio, si bien continúa una herencia de lo que podríamos pensar como una tradición judeo-cristiana occidental, se corre del perdón y la liberación para centrarse en la autonomía.

Todo el pensamiento filosófico y político de los tiempos modernos, tiende a colocar el espíritu humano en un plano superior al real, cava un abismo entre el hombre y el mundo. Al hacer imposible la aplicación de las categorías del mundo físico al mundo espiritual de la razón, coloca el fondo último del

de la ontología a la ética, de pensar que el sujeto antes de comprenderse es sujeto por estar sujetado a otro. Así la ética se convertirá para él en una filosofía primera, marcada por la relación con la alteridad. Innumerables son los análisis al respecto de la ética levinasiana, pero nos resulta ineludible destacar la compilación realizada por Pablo Dreizik (2014), titulada Levinas y lo político. Aquí se condensan múltiples y potentes lecturas a partir de este texto de Levinas, que sirven como disparador para pensar la obra del lituano en su conjunto, pero sobre todo para discutir la dimensión política, ya que como bien reza el artículo de Silvana Rabinovich (2014) en la mencionada compilación, Lévinas "no quiso escribir una filosofía política". Sin embargo, continúa ella que al ver la política como un "mal necesario" Levinas optó por la política "menos grave" que sería el "liberalismo político". Esto es parte central de la discusión del mencionado libro, sobre si el filósofo adhiere o no al liberalismo, discusión por demás interesante pero que excede las pretensiones del presente artículo. 
espíritu fuera del mundo brutal y de la historia implacable de la existencia concreta (Levinas. 2006a, p.11).

Así sentencia Levinas que "el hombre del mundo liberal no elige su destino bajo el peso de la historia" (Levinas, 2006a, p. 12) .

Quien vendrá a ponerle el primer tope a esta noción casi irrestricta de libertad y autonomía será el marxismo, ya que hace hincapié en el peso de la materia. Ya no se puede pensar el ser humano como pura libertad, libre de toda atadura, sino que éste presenta necesidades básicas que lo apremian. Se tienen necesidades materiales que nos recuerdan que la existencia concreta tiene más peso que la autónoma razón.

Así "la libertad absoluta, aquella que realiza milagros, se halla desterrada, por primera vez, de la constitución del espíritu. De ahí que el mismo marxismo se oponga no sólo al cristianismo, sino a todo el liberalismo idealista..." (Levinas, 2006a, p. 12).

No obstante, en el marxismo, la relación del sujeto con su situación no se presenta de un modo totalmente determinante. De hecho, tomar conciencia de esta relación, ya es en alguna medida liberarse del fatalismo que comporta. 6

Si volvemos a la noción de cuerpo específicamente, a lo largo de la historia de la filosofía éste ha sido colocado en una posición inferior, como cárcel del alma, como fuente de pecado, de pasiones, como alejamiento de lo celestial, de lo divino, como aquello que nos ata al mundo terrenal. Aun con posterioridad al Renacimiento, cuando entra en crisis el ideal ascético de vida, la noción de cuerpo como aquello casi prescindible se mantiene, bajo la dualidad cuerpo-razón. Racionalidad que será eje y fundamento de toda la modernidad e incluso después, aunque con las crisis conocidas.

${ }^{5}$ Cabe destacar aquí la lectura que el propio Pablo Dreizik realiza en el artículo titulado "La posibilidad del liberalismo en Lévinas: 'Quelques réflexions sur la philosophie de l'hitlérisme' entre dos lecturas de Husserl”. A partir del análisis de las lecturas de Levinas sobre Husserl en textos inmediatamente anteriores y posteriores al escrito en cuestión, Dreizik afirma -como así también Rabinovich- la adhesión de Levinas al liberalismo. La posibilidad de separación entre el yo y el mundo es lo que le permite una cierta libertad en relación al determinismo del pasado, de la historia o del destino. "La temporalidad trágica del destino y del ser arrojados (Geworfenheit) a la facticidad de la existencia o a la historia, son contestados por Lévinas con esa distancia o retroceso que siempre media entre el sujeto y el mundo" (Dreizik, 2014, p. 97).

${ }^{6}$ En relación con la perspectiva de Levinas del marxismo vale resaltar la lectura de Alejandro Lumerman en su texto titulado: "Lévinas y el marxismo: reflexiones sobre la crisis del humanismo". Al hacer énfasis en la prioridad de la "existencia económica", que el autor marca en varios de sus textos, Lumerman habilita la lectura de un Levinas marxista y reconstruye las discusiones de la época entre marxismo y humanismo (Lumerman, 2014). 
Traemos una vez más las palabras del filósofo lituano que explicitan claramente el proceso por el cual el hitlerismo hace hincapié en la noción de cuerpo, en tanto logra configurar un nuevo tipo de humanidad. Este es el ser engarzado del cual Levinas partirá para proponer la posibilidad de salir de sí, teoría que desarrollará en una obra publicada al año siguiente, titulada De la evasión.

La importancia atribuida a este sentimiento del cuerpo, con el que el espíritu occidental nunca ha querido conformarse, está en la base de una nueva concepción de hombre. Lo biológico, con todo lo que comporta de fatalidad, se vuelve algo más que un "objeto" de la vida espiritual, se vuelve el corazón. Las misteriosas voces de la sangre, los llamados de la herencia y del pasado a los que el cuerpo sirve de enigmático vehículo, terminan perdiendo su naturaleza de problemas sometidos a la solución de un yo soberanamente libre. El yo no aporta más que las incógnitas para resolver estos problemas. Está constituido por ellos. La esencia del hombre no está en la libertad, sino en una especie de encadenamiento. Ser verdaderamente uno mismo...es, sobre todo, aceptar este encadenamiento. (...) Una sociedad de base consanguínea resulta de esta concretización del espíritu. Y entonces, si la raza no existe, jhay que inventarla! (Levinas, 2006a, p.16-17).

Este es el núcleo central de la filosofía del hitlerismo, que viene a insertarse en una sociedad que ha perdido su propio ideal de libertad. Ahora sólo les resta entregarse a la comodidad del fatalismo y recibir el ideal germánico del hombre como una promesa de sinceridad y autenticidad. Ya no se puede elegir mediante una razón soberana y libre, sino que se hallan ligados a una única verdad, la de la determinación biológica, como así también a todos los que son de su sangre. "Encadenado a su cuerpo, el hombre se ve rechazando el poder de salir de sí mismo" (Levinas, 2006a, p. 19). Este tipo de régimen fascista anula cualquier posibilidad de trascendencia, tanto práctica como teórica. Anula cualquier posibilidad de superación de lo real, ya que el hombre en sí está encadenado, a su pasado, a su sangre, a su enquistada identidad.

El vínculo social, a su vez, ya no radica en la decisión de voluntades libres, sino en la exaltación de un pasado común, en aquellos vínculos vividos como más profundos y verdaderos, en aquello que los ata. En definitiva, el vínculo social auténtico no es otro que la comunidad de sangre. Por ello el totalitarismo sienta sus bases en el principio de identidad, pero una identidad fundada en una supuesta determinación biológica, que marca también el destino social. Hay una teleología sostenida en la sangre de la cual esa comunidad no puede escapar. 
Todo esto se postula como verdad y por ello no puede dejar de tener pretensión de universalidad. Propone entonces la creación de un mundo nuevo, de aquel que debe ser regido bajo los parámetros de esta única verdad. Levinas entonces se pregunta: “¿De qué modo la universalidad es compatible con el racismo? Tiene que haber entonces -y está en la lógica de la inspiración primera del racismo -una modificación fundamental de la idea misma de universalidad. Debe hacer lugar a la idea de expansión...que aporta al mismo tiempo su forma propia: la guerra y la conquista" (Levinas, 2006a, p. 12).

Sólo a través de la fuerza es posible esta modificación que hace compatible la universalidad y el racismo.

En estas profundas transformaciones, quizás por eso mismo, imperceptibles, es donde se juega para nuestro autor la humanidad misma del hombre. He ahí la gravedad del asunto que logra poner en palabras cinco años antes del inicio de la guerra, pero que, no obstante, no tuvieron la relevancia necesaria.

De hecho, en un controvertido texto de Petar Bojanić; Las responsabilidades de Lévinas: Reflexiones sobre "Quelques réflexions sur la philosophie de l'hitlérisme", el pensador bosnio carga a Levinas con la responsabilidad de no haber llamado a intelectuales, amigos y demás personas a conformar una especie de lucha preventiva. Ya que aun cuando logró captar los peligros que encarnaba el hitlerismo no movilizó lo necesario para hacerle frente. Comprendemos la postura de este autor, pero no la compartimos ya que Levinas analiza, comprende y denuncia la gravedad que encarna el hitlerismo. Realiza la tarea que le es propia y además lo publica, lo pone a disposición de quien quisiera o pudiera escuchar y comprender el horror que este movimiento entrañaba. De hecho, es parte central de lo que pretendemos poner sobre el tapete, que tanto la denuncia de Levinas como el testimonio de Levi no fueron suficientemente escuchado; quizás por la premura de sus textos, ante una sociedad que no estaba dispuesta ni abierta a intentar comprender el peligro del hitlerismo.

En un exhaustivo análisis que hace Pablo Ríos Flores sobre el mencionado texto de Levinas retoma el artículo de Bojanic en el que sostiene que Levinas más que oponerse al nazismo pretende defender la existencia del judaísmo. Así en la oposición logran una cierta complementariedad que fijaría una identidad, aunque mistificada. Ríos Flores sostiene entonces que:

Si bien esta interpretación de Bojanic permite evitar ciertas lecturas "esencializadoras" u "ontologizadoras" de las reflexiones levinasianas sobre el judaísmo y el hitlerismo, debe ser matizada no obstante con las propias 
palabras del filósofo francés cuyos análisis en los años treinta invitan a un estudio crítico no sólo de un fenómeno complejo como el del nacionalsocialismo sino también de la tradición judía y su particular papel entre las naciones. Ello se evidencia fundamentalmente en los artículos de Paix et droit (Ríos Flores, 2017, p. 134).

Acordamos con esta lectura que complejiza la postura de Levinas aun con el propio judaísmo y que no le endilga una responsabilidad que lo sobrepasaba por mucho. Rescatamos entonces este texto -que actualmente se ha vuelto foco de discusión entre los estudiosos de la temática- ya que, desde nuestra perspectiva, consideramos que es una bisagra en su obra, puesto que es el inicio explícito de su ruptura con Heidegger y su clara apertura a la alteridad y consecuentemente a la ética como filosofía primera. Ética que entra en tensión con la política y que habilita la denuncia que llevó a cabo el filósofo comprometiéndose con su época. La escucha de su análisis acerca del hitlerismo es algo que sin dudas lo excede y que consideramos tiene que ver más con la imposibilidad de comprender, o querer comprender, ese mal elemental.

\section{El testimonio como sostén: la inmediata denuncia de Primo Levi}

Las anticipaciones de Levinas sobre cómo se anula la posibilidad de trascendencia en los regímenes fascistas es parte de la lucha, que consideramos, sostiene Primo Levi. Si la sangre generó tan profundas determinaciones y un destino ineludible para muchos, que, aun no habiendo muerto, quedaron marcados para siempre, ¿por qué no morir? ¿Por qué no suicidarse o solo dejarse morir? ¿Para qué vivir o por qué elegir vivir? Pues para contar el horror, sostiene el italiano. He ahí la recuperación de un espacio de trascendencia, pero sobre todo de libertad, que se había arrasado, pero que sin embargo vuelve a hacerse presente con la fuerza misma de la vida que se sostiene, o quizás justamente se vuelve un modo de seguir sosteniendo la vida, de seguirla eligiendo frente al encadenamiento, de poder elegirla.

"Escritor, judío, superviviente de Auschwitz: cabría decir que esos tres rasgos definen la identidad y el destino de Primo Levi, pero es muy revelador de su carácter que en ninguno de los tres se instalara con comodidad, o sin incertidumbres." (Levi, 2012, p. 9) Con estas palabras comienza Antonio Muñoz Molina el estudio introductorio a la Trilogía de Auschwitz.

Primo Levi nació el 31 de julio de 1919 en Turín y murió en el mismo lugar el 11 de abril de 1987. Sus padres Cesare Levi y Ester Levi habían llegado a Italia a través del sur de Francia luego de la expulsión de España, por lo cual su ascendencia era sefardí. Sin embargo, nunca tuvo formación 
judía. No hablaba hebreo, no vivía en una comunidad segregada y consciente de su diferencia. Si bien había apodos, palabras o recetas de sabor antiguo en su mundo cercano, su familia vivía de manera plenamente asimilada. Tampoco había en Piamonte un antisemitismo demasiado perceptible ni comunidades judías cerradas y numerosas como en el este de Europa: "Como a tantos europeos de su clase y de su generación, a Primo Levi lo volvieron consciente de su condición de judío las soflamas nazis y fascistas sobre pureza de sangre y las leyes raciales, que en la Italia de Mussolini se promulgaron en 1938..." (Levi, 2012, p.11).

Debido a estas leyes raciales, le fue difícil encontrar empleo y trabajó clandestinamente en una mina de asbesto en la región, ya que se había graduado en química en la Universidad de Turín en 1941. Sin embargo, su padre, un ingeniero agnóstico, se afilió al Partido Fascista en los primeros tiempos, sin pensar en que su afiliación y su origen judío comportaran alguna contradicción. En septiembre de 1943 Primo Levi se fue a las montañas para unirse a un grupo de partisanos y en diciembre de ese año fue atrapado por la milicia fascista, que lo entregó al ejército de ocupación alemán al identificarse como judío. El 22 de febrero de 1944 fue deportado y al mes siguiente llegó a Monowitz, uno de los campos de concentración que formaban el complejo de Auschwitz, en Polonia. Pasaron diez meses hasta que el 27 de enero de 1945 los soldados rusos llegaran al campo abandonado por los alemanes y nueve meses más para que el 19 de octubre de ese mismo año Levi regresara finalmente a Turín. Al volver allí trabajó como químico en una fábrica de pinturas hasta jubilarse. Se casó luego de dos años con Lucia Morpurgo, con quien tuvo dos hijos, Lisa y Renzo.

Además de los tres libros sobre Auschwitz escribió algunos libros de relatos, memorias y novelas entre los que podemos mencionar Momentos de indulto, El sistema periódico y Si no es ahora ¿cuándo?, con el que obtuvo varios premios.

Muere en 1987 al caer por el hueco de la escalera de su edificio, hecho que habilita una enorme discusión acerca de la posibilidad de suicidio.

"Químico de día, escritor de noche: muchas veces Primo Levi dijo de sí mismo que se veía como un centauro, una criatura que es dos cosas a la vez y no acaba de ser del todo la una ni la otra" (Levi, 2012, p. 15). Cuando terminaba su jornada en la fábrica se quedaba allí por las noches para escribir a máquina la continuación de su testimonio verbal.

Pero ¿cómo trasmitir lo intrasmisible? ¿Cómo contar? ¿Puede este horror ser contado? Y si lo cuenta, ¿alguien va a creerle, alguien será capaz de escuchar la anticipación de Levinas y la vivencia misma del horror de Levi? 
Así como el filósofo lituano denuncia prematuramente en el 34, Levi testimonia en el 46. Sin editor, con un tiraje ínfimo que se abarrotó durante largo tiempo en algún estante de librería, Levi escribió para trasmitir el horror. Lo hizo con la premura de aquel que quiere contar todo lo sucedido sin perder ningún detalle y eso implicaba un ejercicio de memoria que pensaba podía alterarse con el paso del tiempo. Se convierte en escritor solo como testigo. Si bien admite que muchos de sus amigos no hablaban nunca de Auschwitz, para otros la única razón para vivir era impedir que muriera el testigo, y aclaraba entonces: "Otras personas, en cambio, hablan de Auschwitz incesantemente, y yo soy uno de ellos" (Levi, 1998, p. 172). Y nos cuenta de su necesidad de hablar, de contar cada detalle, de ser escuchado, de dejar un registro fiable de aquel horror, comparándose con un marinero de una vieja balada:

Si usted recuerda la escena, el viejo marinero cierra el paso a los invitados a la boda, que no le prestan atención - ellos están pensando en la boda- y los obliga a escuchar su relato. Pues bien, recién regresado del campo de concentración yo me comportaba exactamente así. ¡Sentía una necesidad irrefrenable de contar a todo el mundo lo que me había sucedido!... Cualquier ocasión era buena para contárselo a todos, tanto al director de la fábrica como al obrero, aunque tuviesen otras cosas que hacer, exactamente como el viejo marinero. Después empecé a escribir a máquina por la noche... Escribía todas las noches, ¡lo cual era considerado algo todavía más insensato! (Levi, 1998, p. 173).

La necesidad irrefrenable de contar lo sucedido lo llevó a escribir. Había en su condición de testigo una responsabilidad que él asumió como ineludible. Esa responsabilidad que, según Bojanic (2014), Levinas no asume - o no completamente ${ }^{7}$, está presente en Levi. No solo por su unión con los partisanos en el 43, sino por su condición de testigo, que hace pública a partir de sus escritos. No obstante, podemos marcar aquí lo mismo que señalamos con Levinas. Sus textos no fueron acogidos en la época, sino recién bastante tiempo después. Y aunque no hubiera espacio de escucha, Levi no abandonó su ejercicio de escribir como forma de testimoniar.

Con el tiempo, nos dice luego, adquirió el oficio de la escritura, pero nunca llegó a considerarse escritor, sino siempre químico. De hecho, cuando escribe otros libros por fuera de sus relatos testimoniales no deja de experimentar un cierto malestar, ya que el sentido de su escritura está en el

${ }^{7}$ Como ya señalamos anteriormente, nos distanciamos de la perspectiva de Bojanic acerca de la responsabilidad de Levinas. Consideramos que sí hubo una asunción de esta y que se manifiesta en el análisis y publicación del mismo. 
testimonio, como forma, podríamos pensar con Levinas, de trascendencia, de ir más allá de la aniquilación de la humanidad que produjo el campo: "En este último libro mío, La llave estrella, me he despojado completamente de mi calidad de testigo... Con esto no reniego de nada: no he dejado de ser un ex deportado, un testigo..." (Levi, 1998, p. 119). "Estoy en paz conmigo mismo porque he testimoniado" (Levi, 1998, p. 219).

Retomamos el testimonio de Levi entre tantos otros posibles por ser el primero en publicarse luego de Auschwitz, ya que lo escribe en el '46 y lo publica en el ' 47 . Sin embargo, es vasta la literatura al respecto y la cantidad de testimonios que podrían analizarse. Nos centramos en Levi por su premura al testimoniar y por su ahínco a pesar de no encontrar interlocutores. Cuestión que, como mencionamos anteriormente, sigue siendo un tema también con el paso del tiempo. De hecho, Ruth Klüger, quien escribe Seguir viviendo recién en 1997, manifiesta la misma preocupación por ese no espacio de escucha, fundamental en el proceso de testimonio. Afirma que: "pensaba que después de la guerra tendría cosas interesantes que contar. Pero la gente no quería oírlo, o sólo con una cierta pose, con una cierta actitud, no como interlocutores, sino como personas que cumplen una tarea desagradable, con una reverencia que se transforma en repugnancia. A distancia" (Klüger, 1997, p. 114).

Distancia porque aquellos sobrevivientes son la marca del horror, distancia porque es preferible no ver, no hacerse cargo de aquello que reclama ser contado y comprendido. "Éramos como enfermos de cáncer, que recuerdan a los sanos que también ellos son mortales" (Klüger, 1997, p. 234) sostiene Klüger al analizar la imposibilidad de la escucha, como esa vivencia límite frente a la que se decide no pensar, pero frente a la cual muchos sobrevivientes necesitan reflexionar críticamente para intentar comprender: comprender qué pasó con sus vidas, con sus nombres, con sus cuerpos, con sus familias, con sus relaciones, con aquello que constituía a cada uno como ser humano.

Si retomamos el análisis de Levinas acerca del hitlerismo, podemos advertir que el proceso de fundamento de la identidad en el nazismo, bajo la apelación al cuerpo y al tiempo, implica a la vez, un señalamiento de la identidad otra que no se ajusta al parámetro establecido y que Levi capta, desde su visión de químico, como ese elemento impuro, que corrompe, que produce alteraciones. Identidades múltiples de judíos, gitanos, ladrones, comunistas, homosexuales, entre otras, como esos elementos impuros, como esas identidades otras que pretenden anular dentro del campo y reducirlas a meros números, eliminando cualquier rasgo propio de esas vidas humanas. 
Al terminar [de vestirnos], nos quedamos cada uno en nuestro rincón y no nos atrevemos a levantar la mirada hacia los demás. No hay dónde mirarse, pero tenemos delante nuestra imagen, reflejada en cien rostros lívidos, en cien peleles miserables y sórdidos. Ya estamos transformados en los fantasmas que habíamos vislumbrado anoche.

Entonces por primera vez nos damos cuenta que nuestra lengua no tiene palabras para expresar esta ofensa, la destrucción del hombre. En un instante, con intuición casi profética, se nos ha revelado la realidad: hemos llegado al fondo. Más bajo no puede caerse: una condición humana más miserable no existe, y no puede imaginarse. No tenemos nada nuestro: nos han quitado las ropas, los zapatos, hasta los cabellos; si hablamos no nos escucharán, y si nos escuchasen no nos entenderían. Nos quitarán hasta el nombre: y si queremos conservarlo deberemos encontrar en nosotros la fuerza de obrar de tal manera que, detrás del nombre, algo nuestro, algo de lo que hemos sido, permanezca (Levi, 2012, p. 47).

Sin ropa, sin cabellos, sin nombre, sin palabra. No hay identidad posible más que la del fantasma. No hay donde mirarse, pero tampoco quieren mirarse. Hay un cierto pudor compartido que les hace negarse la mirada en ese estado de destrucción. La posibilidad de reconocimiento ha sido también aniquilada, pues conservar el nombre implica un esfuerzo extra por recordarlo que trae de la mano el recuerdo de la vida pasada que se les vuelve una pesadilla recurrente en el campo.

Frente al no reconocimiento se da la reificación, frente a la anulación del sujeto la aparición del objeto, que en el mejor de los casos será fuerza de trabajo hasta su extinción. Frente al borramiento del nombre, la marcación del número: "Me llamo 174517; nos han bautizado, llevaremos mientras vivamos esta lacra tatuada en el brazo izquierdo" (Levi, 2012, p. 48).

Y, quizás paradójicamente, será ese número la posibilidad de hacer creíble el testimonio, creíble sí, pero inaudible aun por largo tiempo. Levi sueña con encontrarse a una mujer que habla italiano, le pregunta quién es, él le cuenta lo vivido y ella no le cree nada hasta no ver el número. Esa marca de reificación tatuada en su cuerpo le confiere la condición de sobreviviente, condición con la que no se sentirá cómodo jamás, pues sabe del privilegio que esta implica. Condición que lo obliga a intentar comprender, pero sobre todo una vez más, a habilitar el testimonio como registro ineludible $\mathrm{y}$ trascendencia.

De modo análogo sucede en Klüger, es el número, esa marca en el cuerpo que da cuenta del horror, lo que le habilita pensar en la credibilidad de su relato. Pero porque antes de eso habilita la posibilidad de un futuro y de un 
relato. Es al igual que en Levi la posibilidad de trascendencia: "No hay que quedarse en este ahora tan insoportable. El querer ser testigo significaba lo siguiente: vendrá un tiempo en que esto habrá pasado y este número (A-3537) sólo será indicio, prueba (...) Yo no moriría allí, yo seguro que no" (Klüger, 1997, p. 119). Su cuerpo ha sido cosificado a partir de la inscripción en la piel de un número de serie, pero ella como testigo va más allá del cuerpo. No hay un cierre en la determinación del cuerpo ni del tiempo presente, sino que se puede vislumbrar el futuro en función del testimonio: "Con aquel tatuaje apareció en mí una nueva lucidez, a saber: lo extraordinario, lo monstruoso de mi situación me vino tan violentamente a la conciencia que sentí una especie de alegría. Yo vivía algo de lo que valdría la pena dar testimonio" (Klüger, 1997, p. 118). Así la voluntad como posibilidad de decisión, de libertad, se impone a la determinación que marca el hitlerismo. Como sostiene Simone Weil en sus Cuadernos: "La única arma que tiene la voluntad es, como pensamiento que es, el de poder abarcar los diversos instantes del tiempo, mientras que el cuerpo está limitado al presente" (Weil, 2001, p. 23).

El pesimismo y el optimismo acerca de la posibilidad de sobrevivir variaban de un momento a otro, porque incluso con el tiempo, el hambre y el cansancio reglamentario, la noción de futuro remoto, se volvía imposible. Se trataba de un tiempo acotado que se reducía a la supervivencia inmediata, a la comida próxima, al día siguiente, con suerte a sobrellevar el invierno.

Esa misma acción en la inmediatez implicaba de algún modo la decisión de seguir con vida. Frente a la indiferencia de los días, a la inhumanidad extrema, al sinsentido permanente de pensar que únicamente se saldría de allí por la chimenea, el gesto más cotidiano de aseo representaba una resistencia a la mecánica deshumanizante del campo. Si la pretensión era convertirlos en animales, el acto más nimio de una vida humana sostenía el deseo de seguir con vida. Porque "aun en este sitio se puede sobrevivir, y por ello se debe querer sobrevivir, para contarlo, para dar testimonio" (Levi, 2012, p. 64).

La elección de seguir con vida implica un quiebre no solo con la reificación a la que eran sometidos sino también con el encadenamiento al cuerpo y al tiempo al que adhería el hitlerismo. La voluntad de vida y la afirmación antropológica en Levi responde en alguna medida a la denuncia y advertencia de Levinas al considerar que lo que se juega en el nazismo es la humanidad misma del hombre.

No obstante, no dejan de arremeter en el pensamiento de Levi dos ideas recurrentes, una dentro mismo de su existencia en el campo y otra ya fuera. La primera es la idea de que no le creerían, idea que se presenta en innumerables pasajes, en sueños, al pensarse volviendo a casa, al imaginar 
charlas con su familia. Instancias todas en las que se da cuenta que sus oyentes no lo siguen, que se muestran indiferentes, e incluso se paran y se marchan abandonándolo en un monólogo recurrente.

Consideramos se trata de esta premonición de lo inaudible del horror, de saber que si ni siquiera ellos que estaban allí podían creer que eso era del todo real. Sospechaba, consecuentemente, que el resto de la gente no estaría en condiciones de creer, de escuchar, de hacerle espacio a una verdad muy por fuera de sus parámetros de lo posible, de aquello considerado como posible de ser realizado, de que haya sucedido. ¿Cuánto tiempo fue necesario para empezar a cambiar el registro de lo posible? ¿Cómo fue el proceso de habilitación sensible del horror? ¿Cómo es posible esta habilitación, este cambio en la sensibilidad social que abra la posibilidad de una escucha, de la recepción de lo que necesita ser dicho, sin que esto implique cierta estetización del horror, sin que la experiencia humana concreta se vuelva de algún modo un espectáculo?

Muchos son los debates al respecto, que abren la discusión sobre la representación y la posibilidad o no de arte pos Auschwitz, en los que, sobre todo los pensadores de la Escuela de Frankfurt presentan interesantes aportes.

Rescatamos también aquí la postura de Klüger quien sostiene que no solo es posible el arte pos Auschwitz, sino desde él, ya que la escritura se vuelve ejercicio de resistencia contra la barbarie. Al recordar esto relata: "por dondequiera que estuve recité y compuse poesías. Muchos de los reclusos de los campos de concentración hallaron consuelo en los versos que sabían de memoria. Uno se pregunta en qué consiste en el fondo ese consuelo de la recitación (...) lo que nos daba un apoyo era la forma como tal" (Klüger, 1997, p. 126). En la poesía encuentra su anclaje a lo humano, y una forma de sensibilidad y comprensión que la saca de aquel presente desgarrador: "Quien solo tiene vivencias, sin rimas y sin pensamientos, corre el peligro de perder el juicio. Yo no he perdido el juicio, yo he hecho rimas" (Klüger, 1997, p. 129).

Sin embargo, nos interesa centrarnos en el testimonio de Levi, en su recurrente idea de la no escucha y en la casi profecía autocumplida cuando lleva su primer escrito a la editorial Einaudi, en 1947, y lo rechazan. Pero paradójicamente, quien realiza el informe negativo del texto fue Natalia Ginzburg, escritora, judía, antifascista y esposa de un deportado judío a los campos. Cabe la pregunta, una vez más, por el espacio, por la posibilidad de escucha del horror del testimonio.

La otra instancia que destaca Primo Levi, ya una vez fuera del campo, pensando en la posibilidad misma del testimonio, es acerca de quién logra testimoniar. Los hundidos y los salvados, esa es la distinción. Solo quien se 
salvó puede testimoniar, solo quien logró salir con vida puede contar lo que vio, lo que vivió y encarnar esa categoría incómoda de sobreviviente. No obstante, no deja de saberse privilegiado, no deja de saberse de los pocos afortunados que pudieron vivir para contarlo. De hecho, de su vagón de 45 sólo 4 volvieron a sus casas, lo cual implicó una enorme fortuna.

El problema para Levi, es que los verdaderos testigos no pueden hablar, los que vivieron las cámaras de gas y las múltiples formas de la muerte ya no están y sería necesario para Levi que ese sea el relato, al igual que el de aquellos que sobrevivieron de algún modo, pero que están muertos en vida, que es la figura del musulmán.

No hay relato posible de los hundidos y en función de ello se le vuelve imperiosa su necesidad de testimoniar, aun a sabiendas de que ese testimonio presenta lagunas. Lagunas, sostiene Agamben, en función de quienes no están, en función de eso que no puede ser testimoniado. De esa lengua que no está (Agamben, 2000). Instancia a partir de la cual se habilita el perverso discurso negacionista de que la Shoá es un acontecimiento sin testigos, ya que quienes verdaderamente conocieron el horror de las cámaras de gas no pueden contarlo.

Levi escribe su primer testimonio tomando como modelo los informes semanales que hacía en la fábrica. Pretende lograr una claridad y precisión en la información que le habiliten -en función de su preocupación- la posibilidad de ser escuchado. Semejante horror no necesita ser enfatizado y la eficacia y perdurabilidad del relato de Levi consiste precisamente en el contraste entre la simpleza casi pudorosa de su escritura y las experiencias infernales que testimonia.

Levi logra sin dudas su espacio de escucha, como así también la denuncia de Levinas cobra relevancia. No obstante, ninguno de los dos tiene el eco necesario en su momento. Aun a pesar del rechazo editorial Levi insiste en su actitud ética de compromiso con el otro, con quienes no están para contarlo, con quienes fueron los "verdaderos" protagonistas del horror. Pero también para con quienes sobrevivieron y no pueden hablar y para todos los que estén dispuestos a escuchar el proceso de horror y deshumanización al que llevó este mal elemental.

\section{Conclusión o acerca de anticipaciones y rememoraciones}

Comprender el horror, o la anticipación de aquel, es la tarea que une a ambos pensadores. Cada uno desde su lugar se da a la tarea de pensar, analizar y comunicar aquel proceso. Profeta de lo inmanente, como sostiene Irene Kajón acerca de Levi, pero que podríamos hacer extensivo también a Levinas, en su necesidad de comunicar la articulación de aquellos sentimientos elementales 
en los que se sostenía el hitlerismo y que implicaban un encadenamiento y una determinación frente a la cual había que rehabilitar espacios de libertad $\mathrm{y}$ trascendencia.

Es cierto que el análisis del filósofo lituano implica una cierta profundidad en la que pretende desentrañar cómo se articula ese "estado de ánimo" que denomina hitlerismo y cómo eso se entrama históricamente, sin ser esta la pretensión de Levi. Sin embargo, consideramos que ambos se encuentran en la necesidad de comprensión, en la premura de comunicar aquello que anticiparon o vivieron como desolador y en el hecho de no encontrar un espacio de acogida de esa comunicación tan necesaria.

La preocupación por lo humano los reúne. Esa vocación antropológica y ética los obliga a intentar comprender y a seguir escribiendo; para desentrañar la articulación última del hitlerismo, o para relatar el proceso de deshumanización cotidiana al que fueron sometidos; porque hay una responsabilidad para con aquel que no puede dar testimonio y porque se debe evitar que esto vuelva a suceder.

Vuelve a presentarse la tensión acerca de lo indecible del horror, de aquello que no puede ser contado, frente a lo cual Agamben, leyendo a Levi, sostiene que si nos sostenemos en el camino de lo indecible terminamos otorgándole al horror el prestigio de la mística, cuando en realidad de lo que se trata es de intentar comprender.

En la misma tónica LaCapra (2005) aboga por correrse del carácter traumático totalizador pues esto inhabilita la posibilidad de un examen racional y de la consecuente posibilidad de representación. Si ontologizamos el trauma, el acontecimiento histórico se vuelve incomprensible, inabordable y queda relegado del lado de lo inefable.

El desafío que presentan Levinas y Levi -en momentos muy prontoses el de un intento de comprensión, que le haga frente tanto al misticismo de lo inefable como a la pretendida distancia necesaria para la objetividad moderna. No se trata de centrarse sustancialmente en las instancias materiales, históricas, jurídicas, sino en aquellas donde se juega lo humano, lo ético.

No porque estas otras no sean necesarias, sino porque han sido más recorridas e incluso han propiciado cierta idea de que ya había sido superado el hecho. La comprobación de los hechos, las instancias de los juicios, habilitaron cierta idea de cierre, que lejos está para Agamben de la posibilidad de comprensión en términos humanos (Agamben, 2000, p.18).

Asumimos la perspectiva de Gumbrecht, quien conceptualiza la comprensión como algo procesual, que justamente va cambiando en función de aquella esfera de lo humano que queremos construir. Comprender no es 
entonces solo una capacidad, sino una acción o actualización que implica una responsabilidad, una ética: "Ser capaces de comprender implica elegir qué comportamientos no serán "comprendidos» en aquella esfera de lo humano que queremos construir, no que damos por sentada" (García Ruiz, 2008, p. 182).

Gumbrecht afirma entonces que:

Adjetivar como inhumanos a los campos de concentración supone un ostensible error, puesto que entonces sólo aceptamos que «cuente como» humano aquello que previamente hemos consentido englobar dentro de lo comprensible, tal como «lo comprensible» es dibujado de antemano por el campo perceptivo de nuestra particular antropología. De este modo, toda una gama de acciones, también humanas, que reclaman un abordaje por el pensamiento, quedarían desatendidas (García Ruiz, 2008, p.181).

Esas acciones humanas que reclaman comprensión quedan, a veces, escondidas bajo lo inefable. Quizás porque no nos animamos a mirar el mal a la cara, al intuir que parte de esa estructura está en nosotros. En la complejidad de los testimonios de gente común, en lo que Arendt enuncia como la banalidad del mal, en lo que Levi denomina como zona gris, o en aquellos sentimientos elementales que denuncia Levinas. Aquel espacio donde la larga cadena que une al verdugo con la víctima se rompe y donde no se está más allá del bien y del mal, sino más acá de ellos: "Esta infame región de irresponsabilidad es nuestro primer círculo, del que ninguna confesión de responsabilidad conseguirá arrancarnos y en el que, minuto a minuto, se desgrana la lección de la "espantosa, indecible e inimaginable banalidad del mal" (Arendt, p. 259)". (Agamben, 2000, p. 20) porque es el momento de normalidad el verdadero horror del campo para Levi, aquello que necesita testimoniar para que puedan empezar a desarticularse esos sentimientos elementales que hicieron esto posible. Porque como sostienen ambos autores no se trata de ninguna monstruosidad que habilite misticismos o estetizaciones, sino de un profundo y humano intento de comprensión y en esa vía corren la anticipación y la rememoración de aquel horror. No hay tal monstruosidad sino estructuras que necesitan ser comprendidas y comunicadas, para así poder repensar el ideal moderno de racionalidad del que tanto se jactó Europa. Porque como dice Levi en Los hundidos y los salvados, "ha sucedido, y, por consiguiente, puede volver a suceder; esto es la esencia de lo que tenemos que decir" (Levi, 2012, p.19). 


\section{Referencias bibliográficas}

Agamben, G. (2000). Lo que queda de Auschwitz. PRE-TEXTOS.

Arendt, H. (1999). Eichmann en Jerusalén. Un estudio sobre la banalidad del mal. Lumen.

Bojanic, P. (2014). Las responsabilidades de Levinas. Reflexiones sobre 'Quelques réflexions sur la philosophie de l'hitlérisme'. En P. Dreizik (Ed.), Levinas y lo político (pp. 39-48). Prometeo.

Dreizik, P. (2014). "La posibilidad del liberalismo en Lévinas: 'Quelques réflexions sur la philosophie de l'hitlérisme' entre dos lecturas de Husserl”. En P. Dreizik (Ed.), Levinas y lo político (pp. 87-100). Prometeo.

García González, J. A y Gallardo Cervantes, A. (2001). Bio-bibliografía de Emmanuel Levinas. Contrastes. Revista Interdisciplinar de Filosofia, 6, 263274. https://doi.org/10.24310/Contrastescontrastes.v0i0.1635

García Ruiz, A. (2008). De la historia a la experiencia: los usos de la historia. Daimon, (43), 175-184.

Gumbrecht, H. U. (2001). On the decent uses of History. History and Theory, 40(1), 117-127. https://doi.org/10.1111/0018-2656.00156

Klüger, R. (1997). Seguir viviendo. Galaxia Gutenberg.

LaCapra, D. (2005). Escribir la historia, escribir el trauma. Nueva Visión.

Levi, P. (1998). Entrevistas y conversaciones. Península.

Levi, P. (2012). Trilogía de Auschwitz. Océano.

Levinas, E. (2006a). Algunas reflexiones sobre la filosofia del hitlerismo. FCE.

Levinas, E. (2006b). Humanismo del otro hombre. Siglo XXI.

Levinas, E. (2008). Dificil libertad. LILMOD.

Lumerman, A. (2014). Lévinas y el marxismo: reflexiones sobre la crisis del humanismo. En P. Dreizik (Ed.), Levinas y lo politico. Prometeo.

Rabinovich, S. (2014). Dos éticas en el laberinto político levantino: Buber y Lévinas. En P. Dreizik (Ed.), Levinas y lo político (pp. 293-311). Prometeo.

Ríos Flores, P. (2017). Emmanuel Levinas frente al ascenso de la filosofía elemental del nazismo: un debate metodológico-político. Tópicos, (53), 121-146.

Ríos Flores, P. (2018): El joven Levinas entre dos modos de comprensión de la espiritualidad en la filosofía de entreguerras. En Revista de Filosofía, 43(2), 263-281. https://doi.org/10.5209/RESF.62030

Weil, S. (2001). Cuadernos. Trotta. 
